\title{
FUNCTIONALITY VERIFICATION OF THE DEFORMATION UNITS FOR MEASUREMENT OF WIND SPEED AND DIRECTION
}

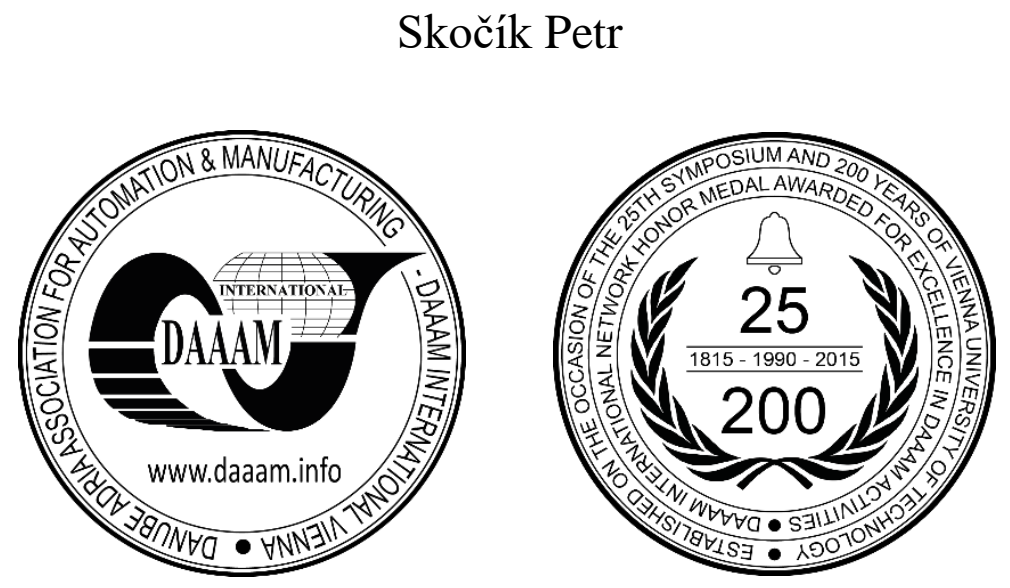

This Publication has to be referred as: Skocik, P[etr] (2018). Functionality Verification of the Deformation Units for Measurement of Wind Speed and Direction, Proceedings of the 29th DAAAM International Symposium, pp.0056-0060, B. Katalinic (Ed.), Published by DAAAM International, ISBN 978-3-902734-20-4, ISSN 1726-9679, Vienna, Austria DOI: $10.2507 / 29$ th.daaam.proceedings.008

\begin{abstract}
This paper is focused on functionality verification of the deformation units which are used for measurement of wind speed and direction. The principle of the method utilizes a balance of strain gauge sensors placed on the deformation unit which are connected to the bridge to achieve low noise, hysteresis and power consumption, high precision and wide temperature range. The sensor responds to the mechanical forces effect to the deformation unit. In this case a semiconductor strain gauges are used. They have a very considerable and accurate change of the electrical resistance with applied mechanical strain. Evaluation of the acting forces is realized as a voltage difference of the strain gauges in the bridge.
\end{abstract}

Keywords: strain gauges; circuit board; mechanical forces; DataLab; ControlWeb

\section{Introduction}

This contribution deals with one of the possible measurement methods of the forces acting in a plain. For this purpose, two deformation units were designed and manufactured. Very sensitive strain gauges were installed on these deformation units. Along with the measuring circuit, it forms the basis for evaluation of wind speed and direction. The design and implementation of the evaluation part is described in the publication [5]. This measuring device will be a part of Photovoltaic model which is the extension of the laboratory of remote real experiments [2]. These educational experiments can be accessed over the Internet and are used for study of industrial automation and applied informatics. The laboratory is placed at the Faculty of applied informatics, Tomas Bata University in Zlín. All models can be remotely used by students and teachers [1].

\section{Theory and measurement principle}

As already mentioned in [5] a nonrotating measurement principle with strain gauges was designed for the measurement of forces in two plains. Two different designs of the deformation units are depicted in Fig. 1 on the left. It is required when the force acts in the $\mathrm{x}$ axis the force in $\mathrm{y}$ axis remains constant and vice versa (see Fig. 1 on the right). The first tested deformation unit is hollow along the entire length. The second one is only narrowed in specific area. The detailed comparison is presented in chapter 4. 
a)

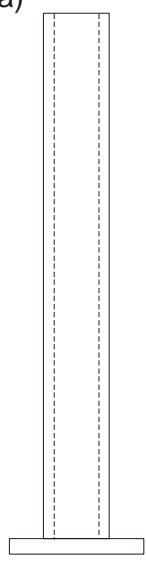

b)

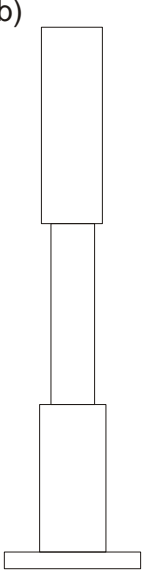

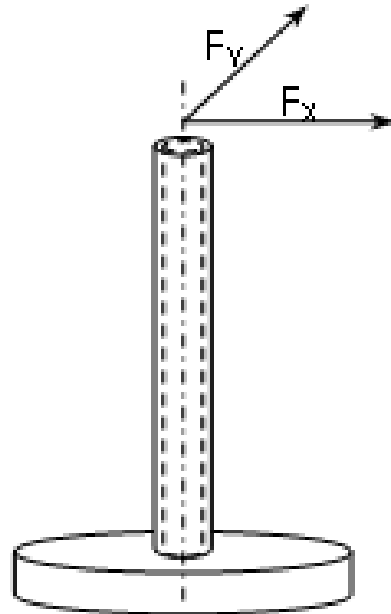

Fig. 1. Tested deformation units and the acting forces

The theoretical basis for determining the forces acting on the deformation unit (Newton Law) incl. the derivation of all related equations is already mentioned in the publication [5], [6], [7].
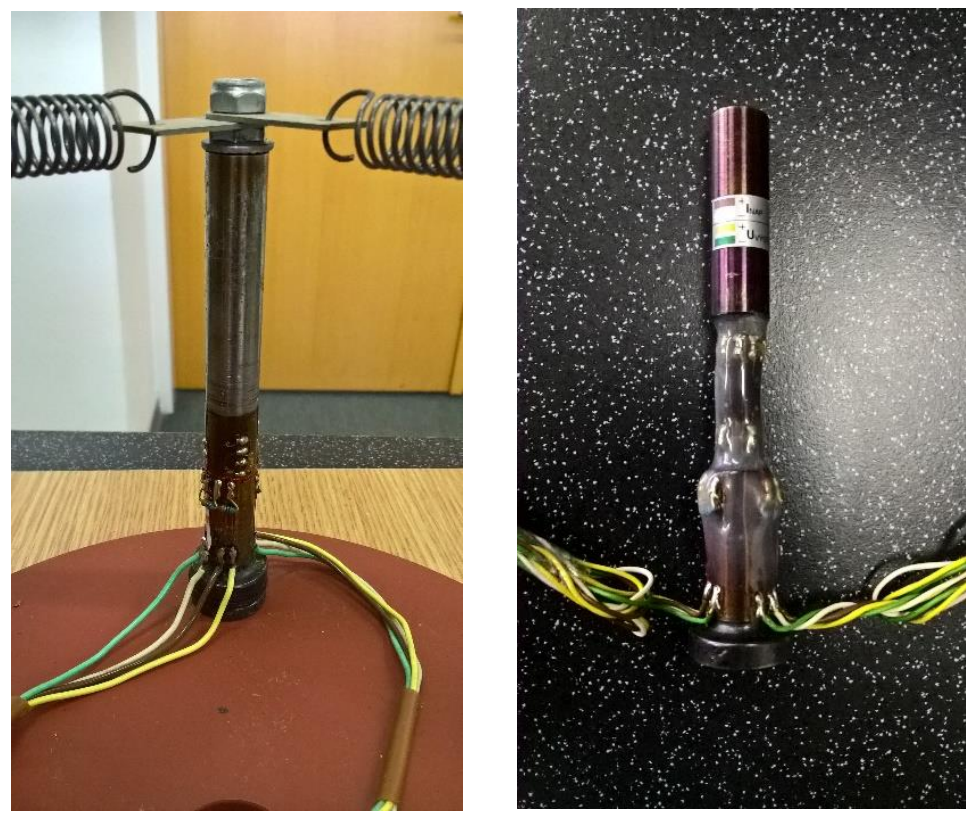

Fig. 2. Deformation units with the strain gauges

As can be seen in the Fig. 2, the strain gauges were implemented on tested deformation units by specialized company. The semiconductor strain gauges are used due to their high efficiency of the conversion of mechanical stress to electric signal [3], [8]. The bridge connection of the strain gauges is used for the measurement of the deformation in both directions $\left(F_{X}, F_{Y}\right)$. The voltage signals $U_{X}, U_{Y}$ are the outputs from both bridges. Forces in the $x$ and $y$ axes are simulated via springs with the length $l$ and constant stiffness $(N / m)$ see Fig. 4.

The deformation unit is always loaded in one direction only. The output signal $U_{X(Y)}$ from both bridges is monitored in dependence on the force $F_{X(Y)}$ or more precisely on the spring length change. The output signal depends on the applied mechanical strain but also on the supply current. Therefore, it is necessary to have the stabilized power supply. The supply current varies depending on the weight of deformation unit.

\section{Electronic circuit design}

The block diagram of the measuring circuit is shown in the Fig. 3. The detailed design and implementation of the measuring circuit can be seen in publication [5]. Evaluation electronic circuits are powered by the symmetrical power supply which give the stabilized voltage for the strain gauges [4]. 


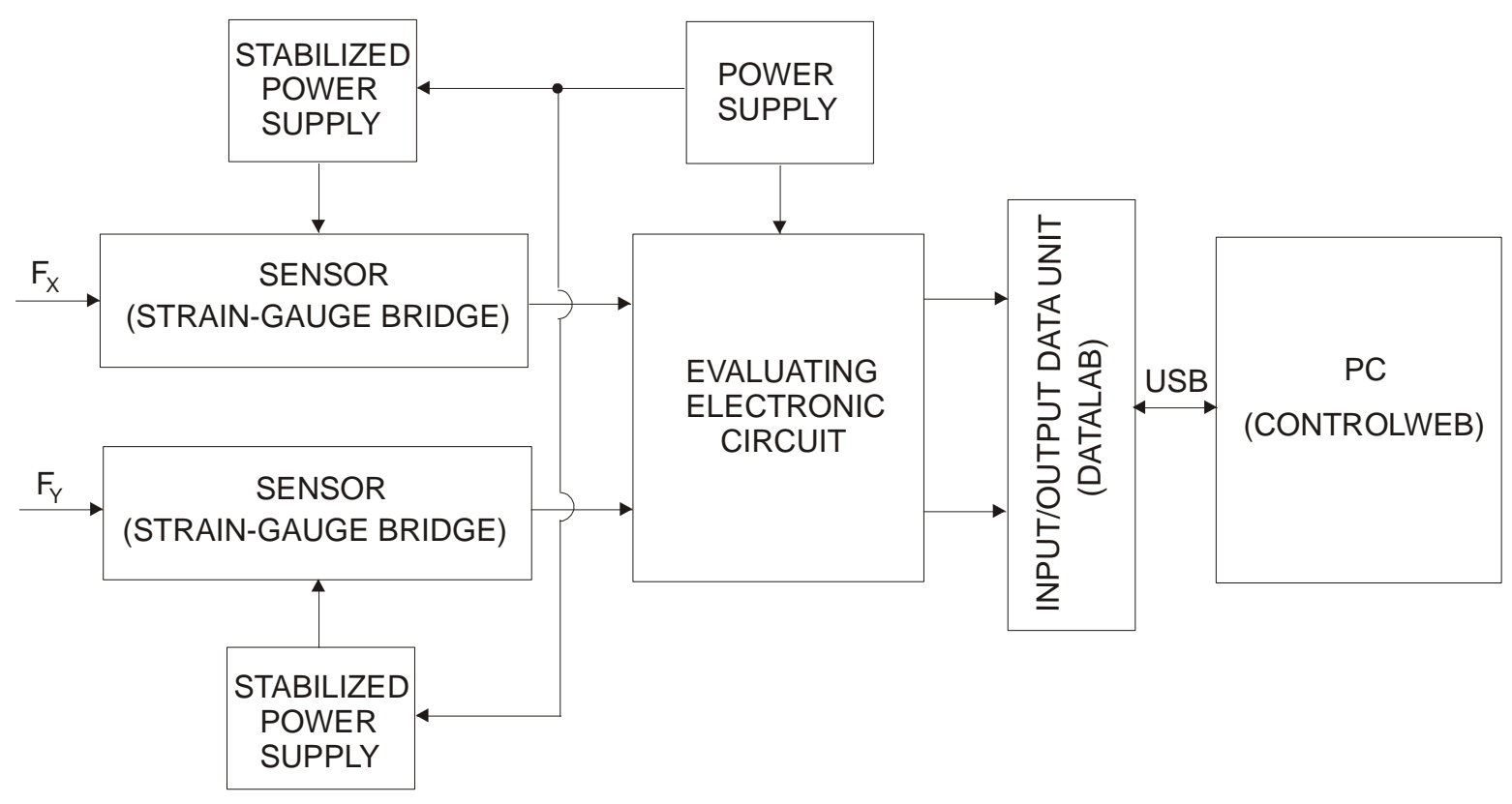

Fig. 3. Block circuit diagram of the measuring system

The deformation unit is loaded in two axes by forces $F_{X}$ and $F_{Y}$. The mechanical strain is measured for both directions by the semiconductor strain gauges in the bridge connection. Both output voltages $U_{X}, U_{Y}$ are adjusted and amplified. These output signals are downloaded through the input/output unit DataLab to the PC where are evaluated and archived in the ControlWeb environment. Communication and data transfer between the PC and DataLab unit is performed through the Universal Serial Bus (USB).

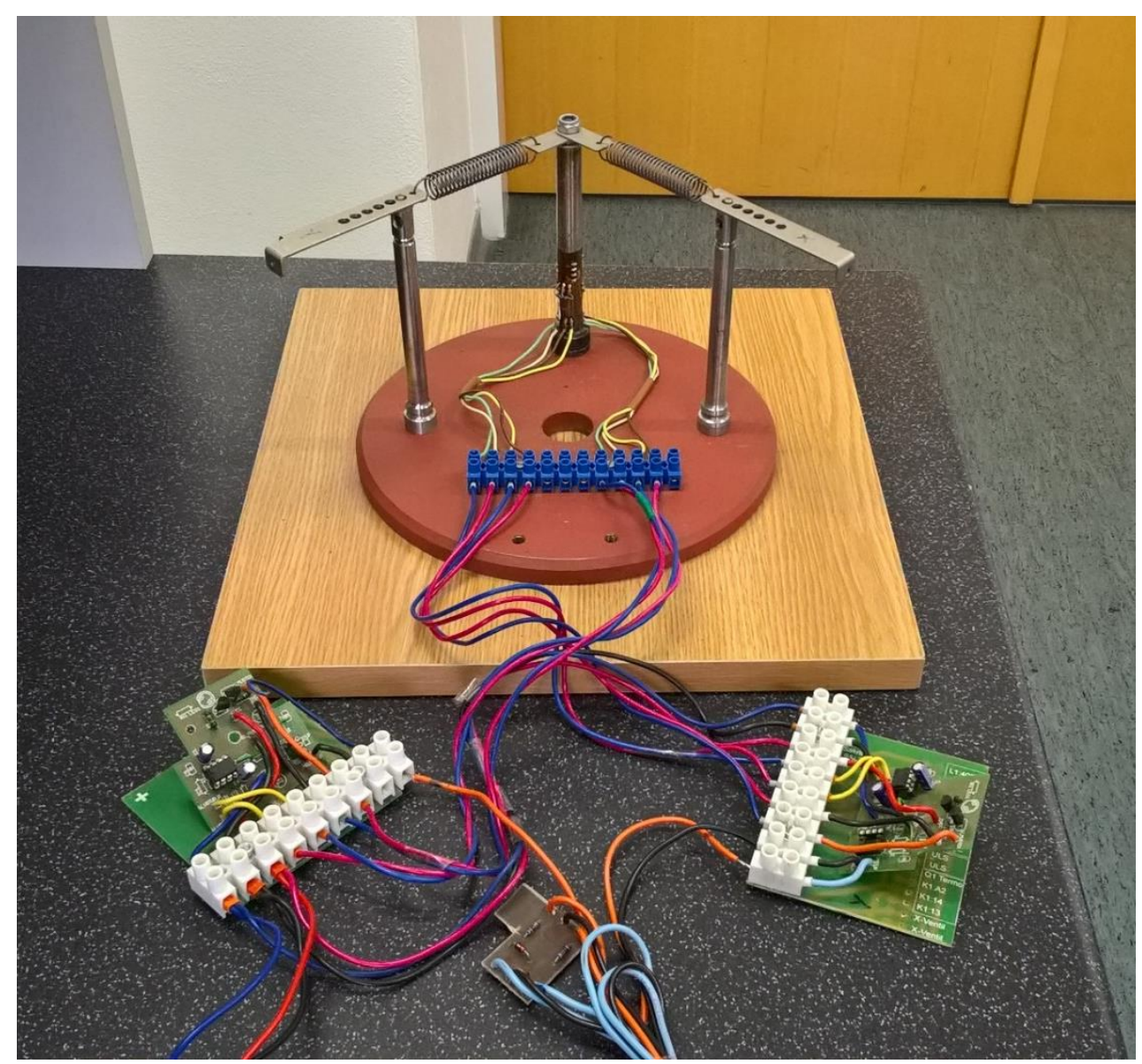

Fig. 4. Measuring system for testing of deformation units 


\section{Discussion of the results}

The measurement was performed for both deformation units (sensors) "A" and "B" (see Fig. 1). The goal of the measurement was to define the sensor sensitivity $\Delta U / \Delta F$ for both force directions $F_{X}$ and $F_{Y}$ and also to evaluate the cross sensitivity where the change of the force acts in one direction and the voltage change is measured in the opposing direction.

After the measurement the average sensitivity $\Delta U_{X(Y)} / \Delta F_{X(Y)}$ of the sensor "A" when the force $F_{X}$ applies is evaluated to $0.047 \mathrm{~V} / \mathrm{N}$. The sensitivity for the force $F_{Y}$ is $0.032 \mathrm{~V} / \mathrm{N}$. As can be seen the sensitivity in $Y$ axis is smaller but both values are suitable. Average cross sensitivity $\Delta U_{Y(X)} / \Delta F_{X(Y)}$ for the force $F_{X}$ is evaluated to $-0.002 \mathrm{~V} / \mathrm{N}$ and for the force $F_{Y}$ to $0.0001 \mathrm{~V} / \mathrm{N}$. The cross sensitivity for the force $F_{Y}$ is very good and for $F_{X}$ is quite suitable. The regression function for the force $F_{X}$ is $y=0.045 x-0.825$ with regression coefficient $R^{2}=0.994$. Regression function for the force $F_{Y}$ is $y=$ $0.031 x-0.303$ with $R^{2}=0.999$. Values solved from the both regression formulas correspond with the appropriate measured values with the good accuracy.

The analysis of the measurement of the sensor " $\mathrm{B}$ " gives following results. The average sensitivity $\Delta U_{X(Y)} / \Delta F_{X(Y)}$ when the force $F_{X}$ applies is $0.158 \mathrm{~V} / \mathrm{N}$. The sensitivity for the force $F_{Y}$ is $0.161 \mathrm{~V} / \mathrm{N}$. The sensitivity for the force $F_{Y}$ is smaller but both values of the sensitivity are suitable. Average cross sensitivity $\Delta U_{Y(X)} / \Delta F_{X(Y)}$ for the force $F_{X}$ is evaluated to $-0.048 \mathrm{~V} / \mathrm{N}$ and for the force $F_{Y}$ to $0.054 \mathrm{~V} / \mathrm{N}$. The cross sensitivity for both forces $F_{Y}$ and $F_{X}$ are quite suitable. The regression function for the force $F_{X}$ is $y=0.157 x-0.762$ with regression coefficient $R^{2}=0.999$. Regression function for the force $F_{Y}$ is $y=0.146 x-0.299$ with $R^{2}=0.963$. Values solved from the both regression formulas correspond with the appropriate measured values with the good accuracy. Comparison of the sensor sensitivity and cross sensitivity for both deformation units is depicted in Fig.

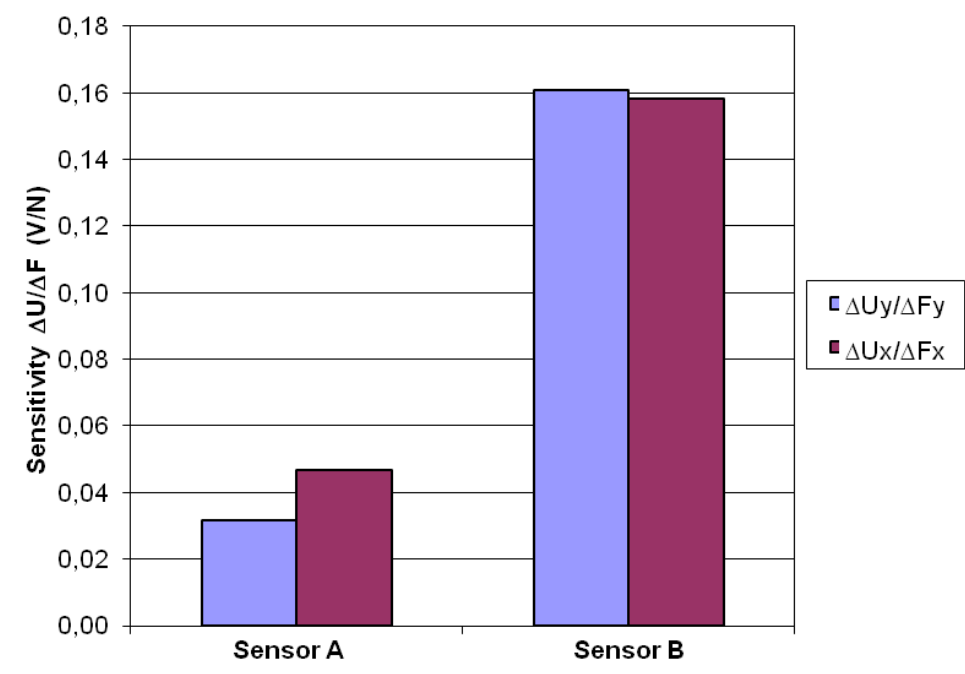

Fig. 5. Sensitivity comparison of the sensors A and B

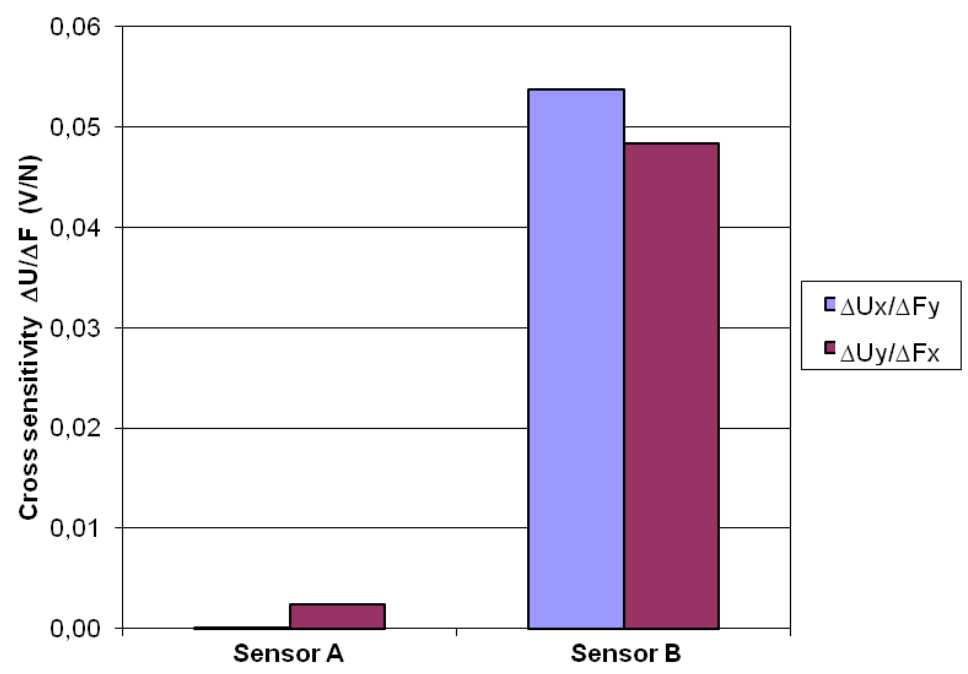

Fig. 6. Cross sensitivity comparison of the sensors A and B 


\section{Conclusion}

The measurement was performed for two tested deformation units. Tests were performed by connection of inputoutput data acquisition module and Control Web program in the development version. Data were presented as relevance between mechanical force and output voltage from the measurement device. The sensitivity and cross sensitivity evaluated in the tests gave positive signal for applying type " $\mathrm{A}$ " sensor in the measuring equipment for speed and direction of wind. Further, a new operation amplifiers have to be used in the evaluation electronic circuit to achieve better parameters (accuracy, sensitivity, offset).

\section{References}

[1] Hruška, F. (2005). New laboratory of integrated automation. In Proceedings of the 16th International DAAAM Symposium, Opatia, Croatia, 19. - 22. October 2005, pp.165 - 166. ISBN 3-901509-46-1.

[2] Hruška, F. (2009). Experimental photovoltaic system. In Proceedings of the 20th International DAAAM Symposium. Vienna, Austria: 25. - 28. November 2009, pp. 923-924, ISBN 978-3-901509-70-4.

[3] *** (2010) http://www.vtsz.cz - VTS Zlin Associated Manufacturers, Semiconductor strain gauges in general and Basic range of our strain gauge, Accessed on: 2011-06-20.

[4] *** (2011) http://www.analog.com/static/imported-files /data_sheets/ADR420_421_423_425.pdf - Analog Devices, ADR421: Ultraprecision, Low Noise, 2.500 V XFET®, Accessed on: 2011-07-01.

[5] Skočík, P. \& Neumann, P. (2011). Circuit design for measurement of force in biaxial area. In Annals of DAAAM for 2011 \& Proceedings of the 22nd International DAAAM Symposium "Intelligent Manufacturing \& Automation: Power of Knowledge and Creativity". Vienna: DAAAM International Vienna, 2011, s. 103-104. ISSN 1726-9679. ISBN 978-3-901509-83-4.

[6] Černý, F.; Samek, L. \& Sopko, B. (2007). Fyzika I. Vyd. 3. přeprac. Praha: Vydavatelství ČVUT, 2007,176 s. ISBN 978-80-01-03650-1.

[7] Svoboda, E. (2006). Přehled středoškolské fyziky. 4., upr. vyd. Praha: Prometheus, 2006, 531 s. ISBN 80-7196-3070 .

[8] Fraden, Jacob. Handbook of modern sensors: physics, designs, and applications. Fifth edition. Cham: Springer, [2016], xix, 758. ISBN 978-3-319-19302-1. 